\title{
Experimental investigation of the effect of Vitagnus plant extract on enhanced oil recovery process using interfacial tension (IFT) reduction and wettability alteration mechanisms
}

\author{
Seyed Ramin Mousavi Dashtaki ${ }^{1} \cdot$ Jagar A. Ali ${ }^{2}$ Abbas Khaksar Manshad ${ }^{3} \cdot$ Iman Nowrouzi $^{4} \cdot$ Amir H. Mohammadi $^{4}$. \\ Alireza Keshavarz ${ }^{5}$
}

Received: 19 May 2020 / Accepted: 27 July 2020 / Published online: 10 August 2020

(C) The Author(s) 2020

\begin{abstract}
Surfactant flooding is a chemical enhanced oil recovery (cEOR) process wherein anionic, cationic, non-ionic, and amphoteric surfactants are injected into oil reservoirs to produce more hydrocarbon. These chemical and industrial agents might cause some economic and environmental challenges. Recently, injection of natural surfactants, as new environmentally friendly EOR agents, for improving oil recovery has been proposed by researchers. In this study, the extract of Vitagnus, a natural surfactant, was used to minimize the interfacial tension (IFT) and alter the rock wettability towards the strong water-wet system, thereby improving the oil recovery from the carbonate rock The conductivity, $\mathrm{pH}$, and turbidity measurements were undertaken to identify the critical micelle concentration (CMC) of the surfactant solutions prepared by mixing 500, 1000, 2000, 3000, 4000, 5000, 6000, and 7000 ppm of the Vitagnus extract and distilled water. The obtained experimental results reveal that the optimum CMC value of the used surfactant was $3000 \mathrm{ppm}$. At this CMC value, the IFT reduced from 29.5 to $5.28 \mathrm{mN} / \mathrm{m}$, and the contact angle of the oil droplet on the surface of the carbonate rock decreased from $114^{\circ}$ to $29^{\circ}$. Accordingly, during the tertiary process, oil recovery was improved from $44 \%$ to $54.6 \%$ OOIP (original oil in place) by injecting 2.25 PVs of the VIT3000 surfactant containing $3000 \mathrm{ppm}$ of the plant extract.
\end{abstract}

Keywords Interfacial tension $\cdot$ Wettability $\cdot$ Core-flooding $\cdot$ Vitagnus $\cdot$ Natural surfactant $\cdot$ Chemical EOR

\section{Introduction}

Tertiary processes of oil recovery are applied to extract the trapped oil from the matured oilfields due to influencing the interactions of fluid/fluid and/or fluid/rock (Ali and Stephen 2018; Ali et al. 2018; 2019a, b, c; Najimi et al. 2019; Asl et al. 2019; Howe et al. 2015). The IFT and the contact angle can be easily reduced by injecting the surfactant solutions into the oil reservoirs (Manshad et al. 2017; Ahmadi and Shadizadeh 2018; Hanamertani et al. 2017; Olayiwola and Dejam 2019). Surfactant flooding is one of the effective cEOR methods that displace the trapped crude oil in the pore spaces towards the production wells (Najimi et al. 2019; Asl et al. 2019). According to Wang et al. (2010), the volumetric sweep (microscopic) efficiency has a great role in the displacement of hydrocarbons at the pore scale, which is affected by the capillary and viscous forces. On the basis of the relationships between these two forces, a number of capillaries are formed, which are controlled by IFT, viscosity, and contact angle (Bera et al. 2013). The

School of Engineering, Edith Cowan University, Joondalup, WA 6027, Australia

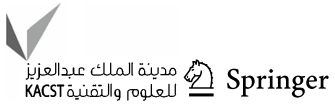


capillary numbers have a direct influence on the oil saturation and production; when this number reaches $10^{-3}$ or $10^{-2}$ for the oil-wet surface and $10^{-6}, 10^{-4}$ or $10^{-3}$, the extraction of the residual oil can be stated and oil saturation can be lowered by $90 \%$ or to zero (Kamal et al. 2015). In order to achieve these favourable values of the capillary numbers, oil-water IFT should be minimized to $20-30 \mathrm{mN} / \mathrm{m}$, which can be usually obtained using surfactant flooding. Moreover, surfactants can have a strong effect on wettability alteration, mobility, and micro-emulsification (Kamal et al. 2015; Kumar and Mandal 2016). The selection of the criteria and performance of the surfactant flooding is dependent on the structure, salinity, and $\mathrm{pH}$ of the surfactant; temperature; and rock properties. The cost of the surfactant, its impact on the environment, and its adsorption behaviour are the main factors of surfactant flooding that need to be considered. Although there are various types of surfactants used in EOR (cationic, anionic, non-ionic, and natural), researchers have recently focused on using natural surfactants as an active EOR agent. In 2009, the pericarp shell of Sapindus Mukurossi fruit was used to reduce the IFT between oil/ water (Chhetri et al. 2009). Later on, Seidlitzia Rosmarinus plant was used as a natural surfactant for improving oil recovery by considering the IFT reduction (Deymeh et al. 2012). Additionally, the leaves extract of Zyziphus Spina Christi plant was used by Ahmadi et al. (2015) as a surfactant EOR flooding in carbonate reservoirs. With increasing the concentration of Zyziphus Spina Christi extract, the recovery factor was increased dependingon the IFT reduction. Furthermore, Kumar and Mandal (2016) and Ahmadi and Shadizadeh (2013a) investigated the role of Glycyrrhiza Glabra \& Mulberry leaves extracts in improving oil recovery from carbonate reservoirs. Consequently, they were enabled to improve oil recovery by 17.8 and 34\% OOIP by injecting surfactants extracted from Mulberry tree leaves and Glycyrrhiza Glabra, respectively. A cedar natural surfactant was also used for the wettability alteration of carbonate and sandstone rocks, and a considerable improvement towards the water-wet state was obtained (Ahmadi et al. 2014).

The ultimate goal of this study was to investigate the influence of the Vitagnus plant extract, as a natural surfactant, on improving oil recovery from carbonate reservoirs. Vitagnus, also called chaste tree or Vitex agnus-castus, is a shrub native to the entire Mediterranean to Western Asia (Fig. 1). In the warm winter region, it grows as a single trunk tree to $6 \mathrm{~m}$ tall or as a vase shaped to 3-4.5 m tall (Daghlian et al. 2016; Mari et al. 2012; Wuttke et al. 2003). The $\mathrm{pH}$, conductivity, and turbidity measurements of surfactant solutions at different concentrations of Vitagnus were used to determine the critical micelle concentration. Additionally, two most important mechanisms of EOR including IFT reduction and wettability alteration were evaluated under the impact of the prepared surfactant solutions using pendant and spinning drop techniques. Then, the improvement of oil recovery factor was identified by conducting the coreflooding test.

\section{Procedure and equipment}

Figure 2 shows a schematic representation of the experimental steps used in the current study, which are mainly divided into four phases: (1) preparation and characterization of the Vitagnus plant extract as a natural surfactant, (2) preparation of the surfactant solutions, (3) identification of the CMC and (4) IFT, wettability, and oil recovery tests under the effect of the used surfactant.

\section{Materials}

Vitagnus, also called chaste tree or Vitex agnus-castus, is a shrub native to the entire Mediterranean to Western Asia.
Fig. 1 Images of the Vitagnus plant

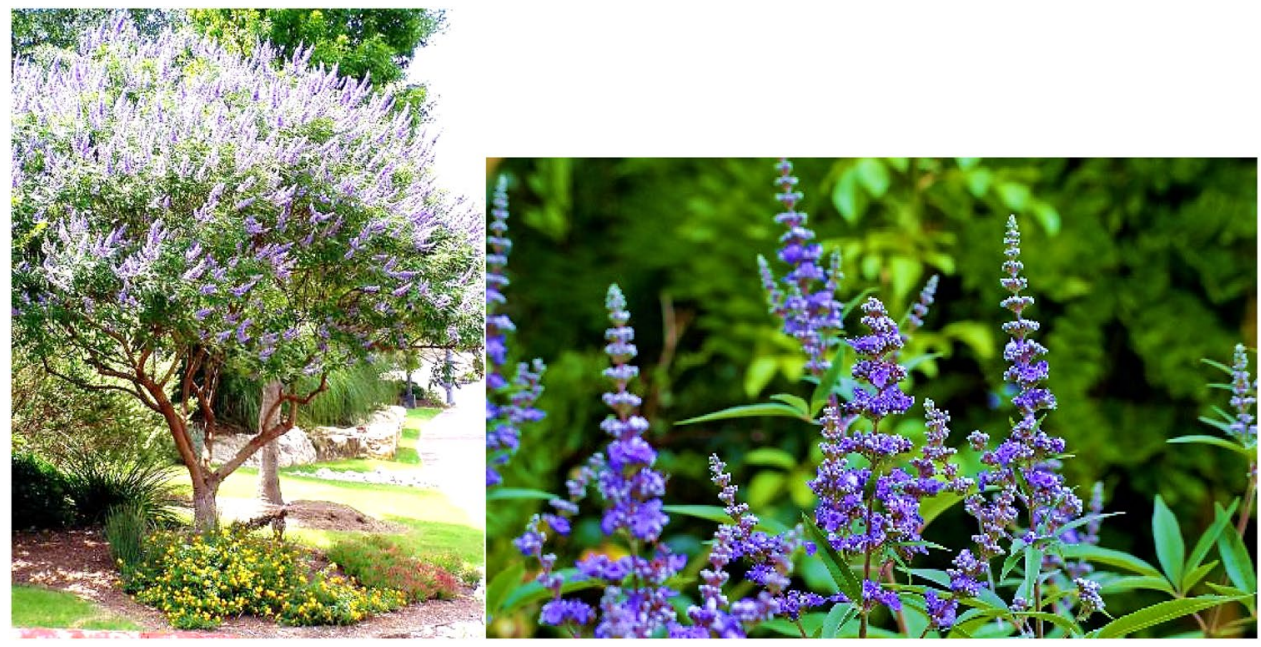




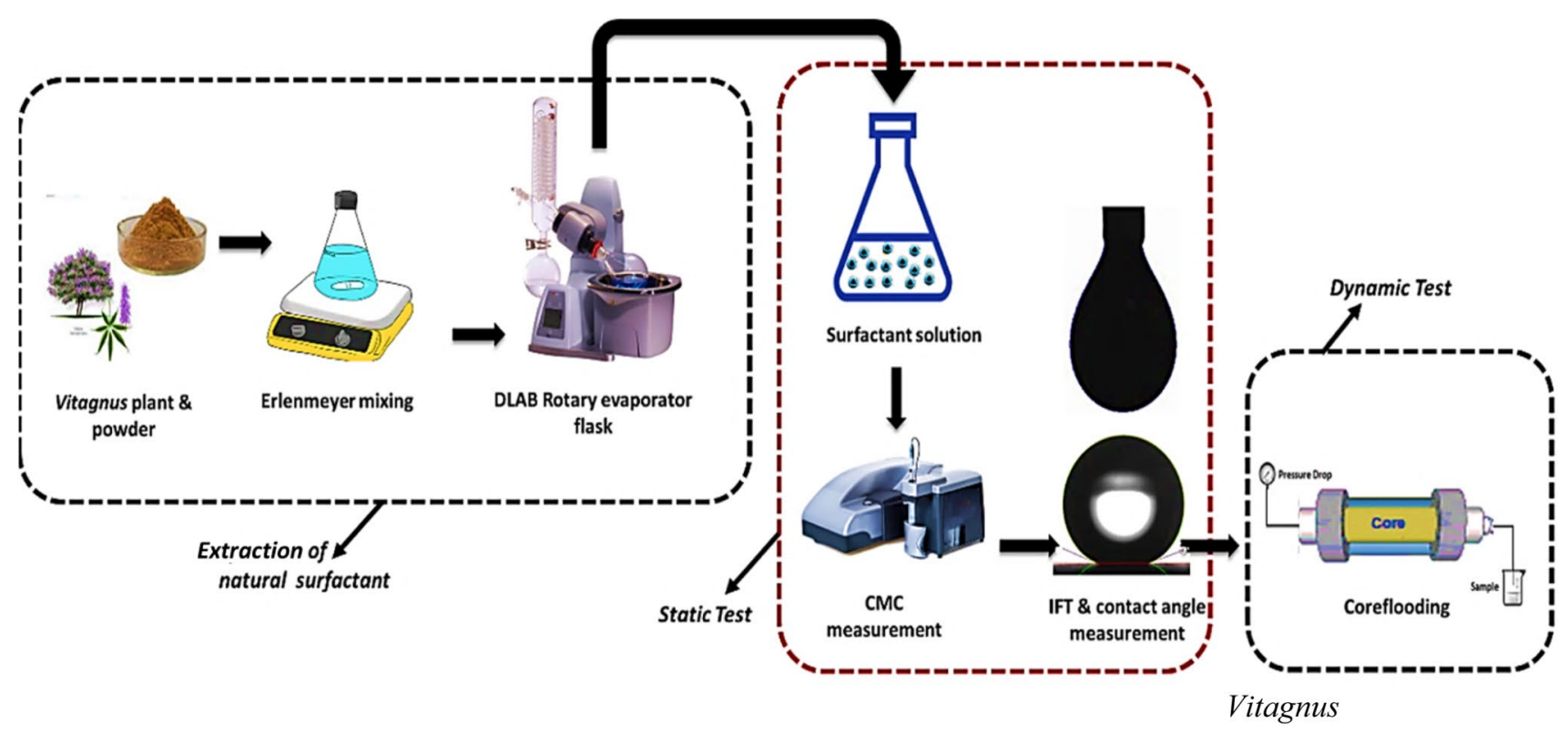

Fig. 2 Schematic representation of the experimental procedures used in the preparation of the Vitagnus plant extract and its application in EOR

In the warm winter region, it grows as a single trunk tree to $20^{\prime}$ tall or as a vase-shaped to $10^{\prime}-15^{\prime}$ tall. However, it is normally grown as a herbaceous perennial to $3^{\prime}-5^{\prime}$ tall in cold winter areas (USDA Zones 5-6) (Mari et al. 2012; Pawar and Kamble 2017). It is widely used in many medical treatments, and its flowers are very attractive to butterflies (Wuttke et al. 2003). Figure 3 shows the general chemical structure of the Vitagnus plant.

Crude oil of $29^{\circ}$ API was collected from the Sarvestan oil field in Iran (Table 1). The density and viscosity of the used crude oil are, $0.875 \mathrm{~g} / \mathrm{cm}^{3}$ and $11 \mathrm{cP}$, respectively. Rock samples were collected from the Asmari Formation outcrop in Khuzestan, Iran, for the wettability measurement and core-flooding. All the chemical reagents used in this study were purchased from Merck Company with purities of approximately 99\%. As shown in Fig. 4, the collected rock sample is carbonate containing $61 \%$ dolomite and $39 \%$ calcite.<smiles>[R9]CC1=C[C@@H](O)C2C=CO[C@H](O)C12</smiles>

$\mathrm{R}=\mathrm{glc}$ aucubin $\mathrm{R}=p-\mathrm{OH}-\mathrm{Ph}-\mathrm{CO}-$ agnuside<smiles>[R6]c1cc(-c2oc3c([R])c([R6])c([R])c(O)c3c(=O)c2[R])cc([R6])c1[R20]</smiles>

$\mathrm{R}_{1}=\mathrm{H} ; \mathrm{R}_{2}=$ glc; $\mathrm{R}_{3}=\mathrm{R}_{4}=\mathrm{H} ; \mathrm{R}_{5}=\mathrm{OH} ; \mathrm{R}_{6}=\mathrm{R}_{7}=\mathrm{H}$ homorientin

$\mathrm{R}_{1}=\mathrm{H} ; \mathrm{R}_{2}=$ glc $; \mathrm{R}_{3}=\mathrm{R}_{4}=\mathrm{R}_{5}=\mathrm{R}_{6}=\mathrm{R}_{7}=\mathrm{H}$ isovitexin

$\mathrm{R}_{1}=\mathrm{R}_{2}=\mathrm{R}_{3}=\mathrm{H} ; \mathrm{R}_{4}=\mathrm{glc} ; \mathrm{R}_{5}=\mathrm{OH} ; \mathrm{R}_{6}=\mathrm{R}_{7}=\mathrm{H}$ orientin

$\mathrm{R}_{1}=\mathrm{R}_{2}=\mathrm{H} ; \mathrm{R}_{3}=$ glc; $\mathrm{R}_{4}=\mathrm{R}_{5}=\mathrm{R}_{6}=\mathrm{H} ; \mathrm{R}_{7}=\mathrm{OH}$ luteolin 7-O-glucoside

$\mathrm{R}_{1}=\mathrm{R}_{2}=\mathrm{OCH}_{3} ; \mathrm{R}_{3}=\mathrm{CH}_{3} ; \mathrm{R}_{4}=\mathrm{H} ; \mathrm{R}_{5}=\mathrm{OH} ; \mathrm{R}_{6}=\mathrm{CH}_{3} \mathrm{R}_{7}=\mathrm{H}$ casticin

Fig. 3 Chemical structure of Vitagnus (Mari et al. 2012) 
Table 1 Crude oil components

\begin{tabular}{ll}
\hline Component & Molar percentage \\
\hline Propane & - \\
$i$-butane & - \\
$n$-butane & 4.59 \\
$i$-pentane & 11.66 \\
$n$-pentane & 18.92 \\
2-methyl pentane & 16.28 \\
3-methyl pentane & 7.45 \\
n-hexane & 19.47 \\
Methyl cyclopentane & 8.12 \\
Benzene & 5.18 \\
Cyclopentane & 1.46 \\
1,1-dimethyl cyclopentane & 5.06 \\
Other isomers & 1.81 \\
Total & 100.00 \\
\hline
\end{tabular}

\section{Preparation of Vitagnus plant extract and its surfactant solutions}

The extract of the Vitagnus plant was obtained using the maceration process (see Fig. 2). First, the Vitagnus plant was dried at room temperature and crushed to a powder using mortar and pestle. Next, $500 \mathrm{~g}$ of the dried plant powder was mixed with distilled water in an Erlenmeyer flask and kept for 3 days. The orbital shaker (KS260 model) manufactured by IKA was used to shake the Erlenmeyer flask from time to time in order to keep mixing the powder with water and obtain an extract with high purity. Thereafter, the achieved extract solution was filtered with filter paper and was transferred into the DLAB rotary evaporator flask for $3 \mathrm{~h}$ to obtain a dry extract powder with high purity. Then, the surfactant solutions (VIT0, VIT500, VIT1000, VIT2000, VIT3000, VIT4000, VIT5000, VIT6000, and VIT7000) were prepared by dispersing the obtained powder of the Vitagnus plant within distilled water at different concentrations ranging from 500 to $7000 \mathrm{ppm}$ (Table 2). The mixing was done in a beaker for 30-60 min using a magnetic stirrer
Fig. 4 XRD analysis of the used carbonate rock
Table 2 Formulation of Vitagnus surfactant solutions used in this study

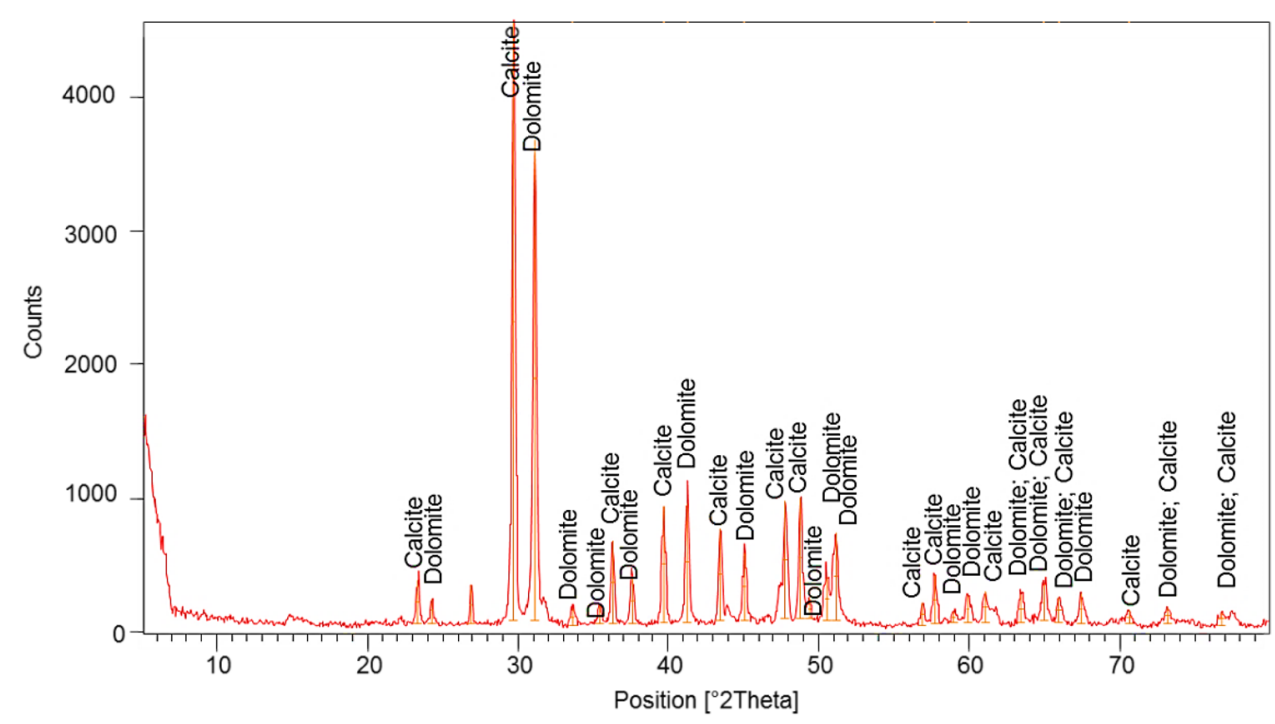

\begin{tabular}{lcllcc}
\hline VIT solution & $\begin{array}{l}\text { Surfactant concen- } \\
\text { tration }(\mathrm{ppm})\end{array}$ & Density $\left(\mathrm{g} / \mathrm{cm}^{3}\right)$ & Turbidity & $\mathrm{pH}$ & $\begin{array}{c}\text { Conductiv- } \\
\text { ity }(\mu \mathrm{s} / \mathrm{cm})\end{array}$ \\
\hline VIT0 & 0 & 0.9950 & 1 & 5.95 & 6 \\
VIT500 & 500 & 0.9971 & 7.46 & 5.07 & 79 \\
VIT1000 & 1000 & 0.9970 & 20.2 & 5.12 & 79.2 \\
VIT2000 & 2000 & 0.9968 & 12 & 4.70 & 84 \\
VIT3000 & 3000 & 0.9961 & 71.3 & 4.72 & 91.7 \\
VIT4000 & 4000 & 0.9957 & 39.3 & 4.98 & 96.7 \\
VIT5000 & 5000 & 0.9957 & 43.7 & 4.99 & 97.3 \\
VIT6000 & 6000 & 0.9945 & 99.9 & 5.00 & 131.8 \\
VIT7000 & 7000 & 0.9960 & 63.0 & 4.69 & 133.4 \\
\hline
\end{tabular}

مدينة الملك عبدالعزيز KACST 
(MR3001K). In order to identify the CMC of the Vitagnus surfactant, the electrical conductivity, turbidity, and $\mathrm{pH}$ characteristics of the surfactant solutions were measured using a JENWAY-4510 conductivity meter, an AL250T-IR turbidity meter, and a Mettler Toledo $\mathrm{pH}-m e t e r$, respectively.

\section{IFT and contact angle}

The pendant and spinning drop methods were used to measure the IFT and the contact angle by VIT- 6000 apparatus manufactured by Fars EOR Technologies Company (Fig. 5). This apparatus consists of two sample holders (bulk fluid and drop) connected to pumps used to adjust the pressure. Some valves are present on the device for different purposes, such as a dropped valve for producing the oil droplet through the metal needle $(2.05 \mathrm{~mm})$, two glass valves opposite the CCD camera (HD-2 MegaPixels) and lighting, and highpressure valves. Additionally, the device is connected to a computer equipped with a software to express and analyse the measured data. Basically, the sample holders are filled with the bulk liquid by using a manual handle pump, and the mutual pump is used to generate an oil droplet inside the bulk liquid from the needle under the atmosphere and reservoir conditions of up to $3000 \mathrm{psi}$ and $180{ }^{\circ} \mathrm{C}$.

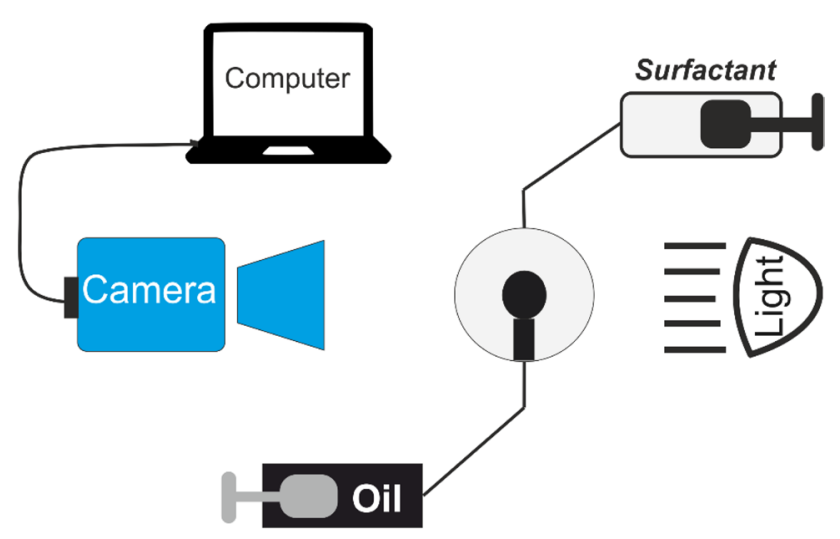

Fig. 5 Schematic representation of VIT-6000 apparatus used to measure IFT and contact angle

Fig. 6 Schematic representation of the theory behind the estimations of IFT and wettability behaviour of rock-fluid/fluidfluid systems: a IFT shape drop and $\mathbf{b}$ wettability conditions (Teklu et al. 2017)
The pendant drop, as one of the most common methods, was used to measure the static and dynamic IFTs between a light phase (crude oil) and a heavy phase (surfactant solution). The IFTs between the crude oil and the surfactant solutions with different concentrations (500-7000 ppm) were measured using the pendant drop technique and the droplet shape analysis (Fig. 5). The IFTs of the crude oil droplet within the distilled water and the prepared surfactant solutions were measured. In this method, the shapes of the crude oil within the surfactant solutions were captured by the HD camera and analysed using the following equation to measure the IFT values (Pawar and Kamble 2017):

$\sigma=\frac{\left(\Delta \rho * g * D^{2}\right)}{H}$

where $\Delta \rho$ is the density difference (crude oil and surfactant solution), $g$ is the gravitational acceleration, $D$ is the maximum droplet diameter, and $H$ is the coefficient of the droplet shape (Fig. 5).

Additionally, the wetting behaviour of the used carbonate rock samples with the presence of two phases (hydrocarbon and surfactant solution) was identified by measuring contact angles of a crude oil droplet on the rock surface with/ without the presence of the surfactant solutions (see Fig. 6). For this purpose, the carbonate rock samples were cut into thin sections ( $25.4 \mathrm{~mm}$ diameter and $3 \mathrm{~mm}$ thickness). The prepared rock plates were polished and cleaned inside the Soxhlet using toluene for 1 day. In order to obtain the oilwet system, the dried rock plates submerged into the crude oil for 12 days at $70{ }^{\circ} \mathrm{C}$. After the ageing of each section in the surfactant solutions, contact angle tests were conducted using the VIT-6000 device (see Fig. 5) to identify the state of the wetting behaviours of the used rocks according to the phenomenon shown in Fig. 6b.

\section{Core-flooding test}

The experimental apparatus used in this study for conducting the oil recovery test is schematically illustrated in Fig. 7; it consists mainly of the built pumps, a core holder (maximum

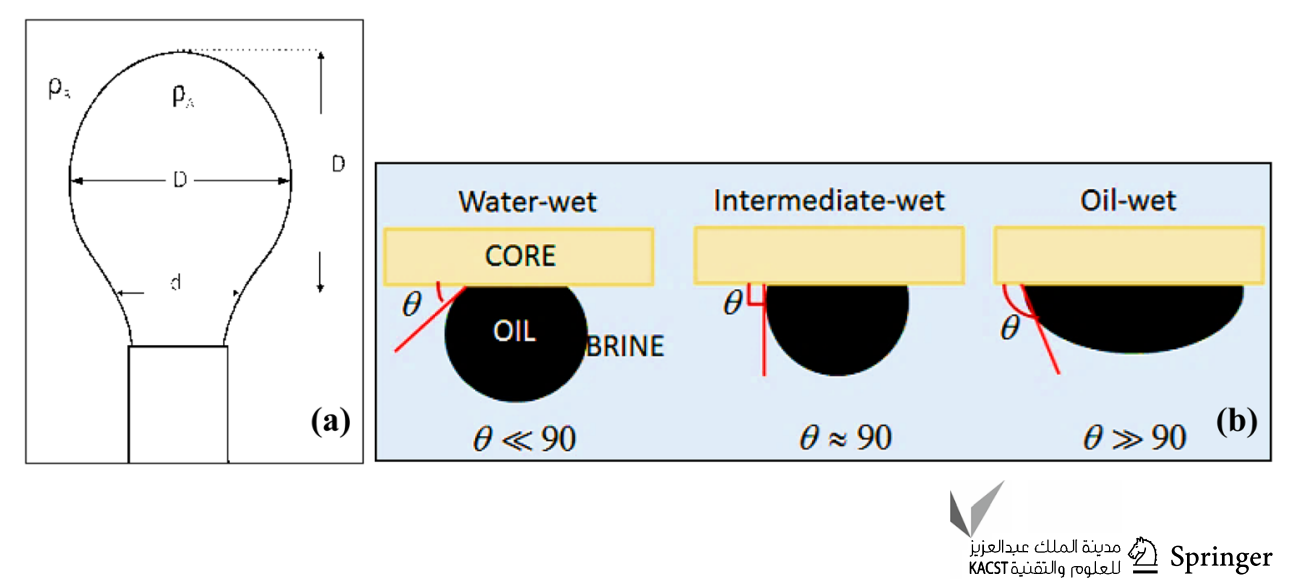




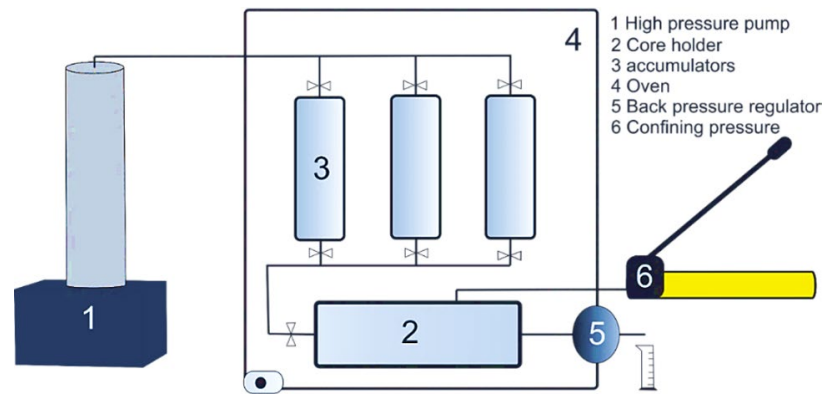

Fig. 7 Schematic representation of the core-flooding apparatus

length of $8.5 \mathrm{~cm}$ and maximum diameter of $3.5 \mathrm{~cm})$, tanks (crude oil and injection fluids), a collector vessel (to collect the produced oil), and some gauges and values. From the tanks (sample chambers), the fluids were pumped into a core sample. All the flooding tests were carried out at $70{ }^{\circ} \mathrm{C}$ and 2000 psi. Along with that of the core holder, the temperature of the fluid tanks was controlled inside an oven. The core plug used was a carbonate rock with a porosity of $11 \%$ and permeability of $3.2 \mathrm{mD}$, taken from Asmari formation outcrop and cleaned using Soxhlet extraction for $24 \mathrm{~h}$ with toluene and oven-dried for $24 \mathrm{~h}$ at $120{ }^{\circ} \mathrm{C}$.

In order to establish the saturation profiles inside the prepared core, initially, the core sample was placed inside the core holder and the brine accumulator was connected to the core holder; then, a confining pressure of 1000 psi greater than the injection pressure was applied. After connecting the coreflooding system, the brine was injected with $0.25 \mathrm{~cm}^{3} / \mathrm{min}$ rate by fluid injection pump. Before setting the cores inside the core holder, the dead volume of the core holder and tubes was measured. Afterwards, oil accumulator was connected to the core holder instead of the brine accumulator and the confining pressure was applied to the core. Then, crude oil was injected into the core sample at different rates from 0.1 to $0.5 \mathrm{~cm}^{3} / \mathrm{min}$ and the produced water was measured in a graduated flask. After occurring the breakthrough, extra 2 pore volumes (PVs) of crude oil were injected to complete the saturation process. Furthermore, the core displacement was begun by injecting 2 PVs of the brine collected from the Persian Gulf. Then, 2 PVs of the VIT3000 solution as the tertiary recovery were injected into the core plug. Both the displacements were done at the injection rate of $0.5 \mathrm{~cm}^{3} / \mathrm{min}$, and the pressure was monitored by two pressure transducers at the inlet and the outlet of the core holder. The volume of the collected oil was used to determine the recovery factor (RF) of both floodings.

\section{Results and discussion}

\section{Spectral characterization of Vitagnus surfactant}

According to Saha et al. (2018), the Thermogravimetric Analysis (TGA) and Fourier Transform Infrared pectroscopy (FTIR) analyses were carried out to evaluate the validity and stability of Vitagnus (Fig. 8). The result of the FT-IR analysis of the Vitagnus extract is shown in Fig. 8a. The current FT-IR spectrum indicates the probable phytoconstituents of the Vitagnus plant. The very broad trough of the $\mathrm{O}-\mathrm{H}$ stretch reveals the hydroxyl compounds of the extract at $3604 \mathrm{~cm}^{-1}$ (Wuttke et al. 2003). The absorption band of the $\mathrm{C}-\mathrm{H}$ vibrations of the extract is at $2893 \mathrm{~cm}^{-1}$, which identifies the aliphatic hydrogen ions. The organic compounds bonds including the $\mathrm{C}-\mathrm{H}$ stretch are identified at the 2893 and $2979 \mathrm{~cm}^{-1}$ wavenumber. The carbonyl stretching vibration bands $\mathrm{C}=\mathrm{O}$ and $\mathrm{C}=\mathrm{C}$ stretches of the saturated aliphatic ketones appear at 2122 and $1654 \mathrm{~cm}^{-1}$, respectively. Moreover, the $\mathrm{C}-\mathrm{O}$ stretching band could be observed on the peaks with the wavenumber lower than $1451 \mathrm{~cm}^{-1}$. The main strong absorption peaks in this spectrum are the alcohol bond $(\mathrm{O}-\mathrm{H})$ and the carbonyl double bond $(\mathrm{C}=\mathrm{C})$. TGA curve (Fig. $8 \mathrm{~b}$ ) reveals that Vitagnus is thermally full stable up to $30{ }^{\circ} \mathrm{C}$ and its thermal stability reduces by $90 \mathrm{wt} \%$ at $100{ }^{\circ} \mathrm{C}$. In addition, about $99 \mathrm{wt} \%$ of the sample is changed at temperature of $300{ }^{\circ} \mathrm{C}$. This reveals that the used surfactant is extracted from the plant and it is natural.

\section{Characterization of VIT-surfactant solution}

The critical micelle concentration of the surfactant can be figured out using various approaches including the IFT, conductivity, gravimetry, and surface tension. In this study in accordance with Ahmadi and Shadizadeh (2013b), we considered the electrical conductivity approach to identify the CMC of the developed natural surfactant (VIT solution). To obtain this, several solutions of the raw surfactant were prepared in the range of 500-7000 ppm. The measured results of conductivity property are demonstrated in Fig. 9. As can be seen, the optimum CMC of the surfactant from the conductivity results was approximately $2930 \mathrm{ppm}$. Accordingly, $3000 \mathrm{ppm}$ was estimated as the optimal CMC of the Vitagnus extract to be mixed with distilled water. It was also clear that the colour of the solution became darker with an increase in the concentration of the Vitagnus extract within the distilled water, as shown in Fig. 10. 
Fig. 8 The characterization of the Vitagnus extract; a FTIR and $\mathbf{b}$ TGA
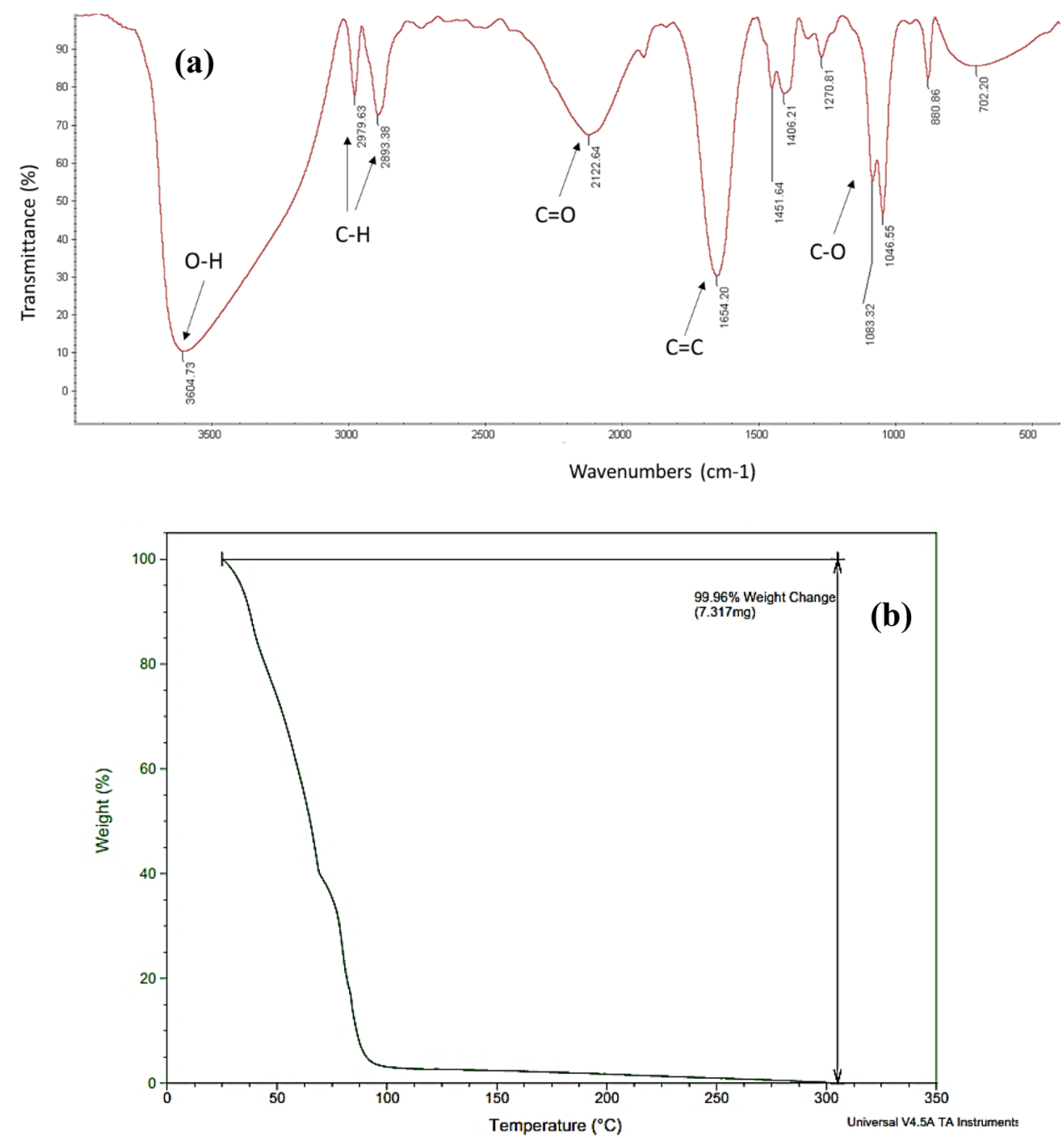

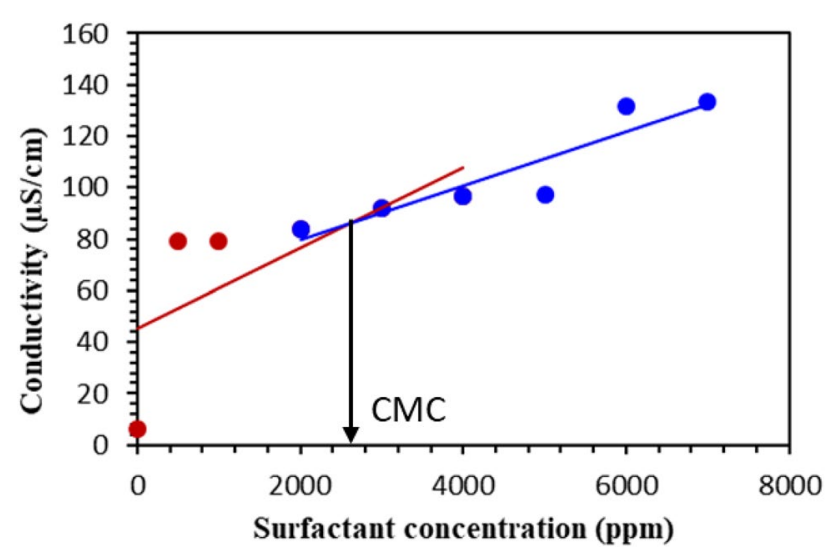

Fig. 9 CMC of the Vitagnus surfactant estimated using the conductivity measurment

\section{IFT measurement}

Figure 11 shows the static, dynamic, and photographic IFTs results of the Vitagnus surfactant solutions. Surfactant solutions were prepared using different concentrations of the plant extract, including 500, 1000, 2000, 3000, 4000, 5000, 6000, and $7000 \mathrm{ppm}$. The value of IFT was rapidly decreased by adding $500 \mathrm{ppm}$ of the surfactant to distilled water from 29.5 to $5.4 \mathrm{mN} / \mathrm{m}$ (Fig. 11). With an increase in the surfactant concentration, the IFT value slightly increased and decreased. Thus, no linear trend of the IFT curve with the surfactant concentration was achieved, while the minimum IFT of $1.87 \mathrm{mN} / \mathrm{m}$ between the crude oil and VIT5000 was identified when $5000 \mathrm{ppm}$ of the Vitagnus extract was added to distilled water. In overal, IFT was reduced by $93.6 \%$ by adding $5000 \mathrm{ppm}$ of the Vitagnus extract to the distilled water, while IFT was decreased by $65.4 \%$ by increasing the concentration of the used natural surfactant from 500 to $5000 \mathrm{ppm}$. 
Fig. 10 Prepared surfactant solutions in transparent sample containers

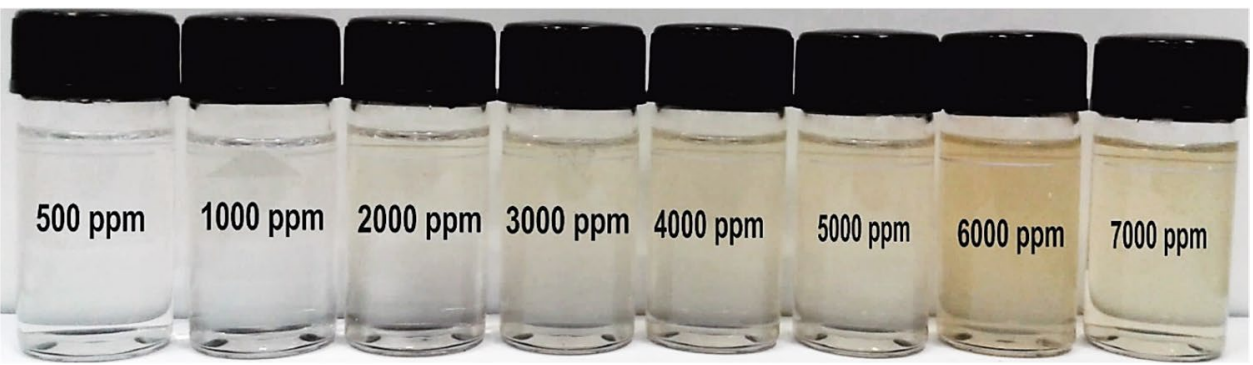

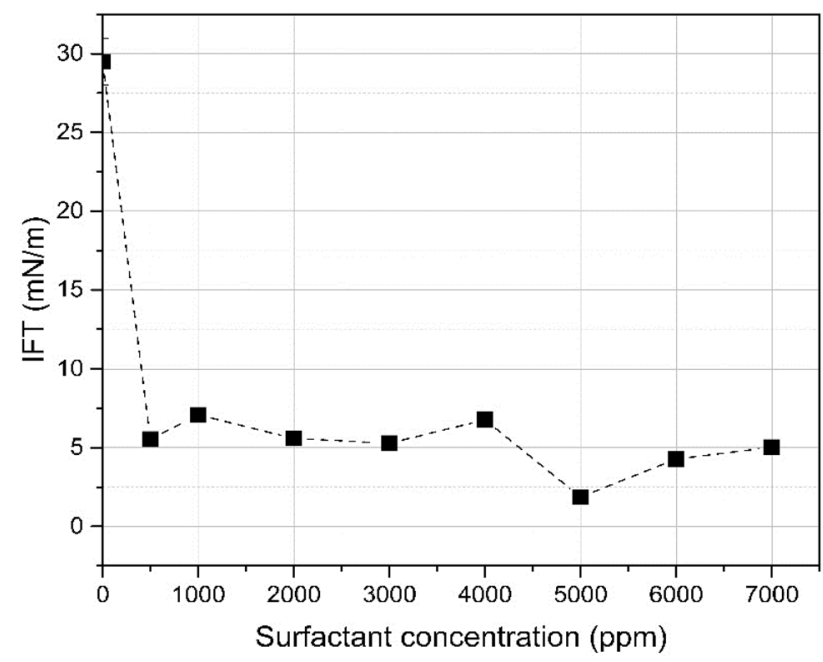

Fig. 11 IFT values measured between crude oil and Vitagnus surfactant solutions at concentrations of 500-7000 ppm
The dynamic IFT curves of the different crude oil-Vitagnus surfactant systems are shown in Fig. 12. As is clear, all the IFT curves for the crude oil-surfactant solution systems (oil-VIT500, oil-VIT1000, oil-VIT2000, oil-VIT3000, oil-VIT4000, oil-VIT5000, oil-VIT6000, and oil-VIT7000) have a clear trend with time. For each individual system, the IFT continuously decreases with an increase in the test time from its high value to its minimum value. This is considerably consistent with the experimental results obtained by Pal et al. (2018), Najimi et al. (2019), and Asl et al. (2019). As is obvious, the lowest dynamic IFT curve was recorded for the crude oil-VIT5000 system; the IFT starts from 13.21 $\mathrm{mN} / \mathrm{m}$ at the first second of the test and gradually minimizes to $1.87 \mathrm{mN} / \mathrm{m}$ at $5450 \mathrm{~s}$. However, the highest values of dynamic IFTs through the entire test period were obtained with the VIT1000 surfactant solution compared with other solutions, which start from $18.6 \mathrm{mN} / \mathrm{m}$ and decrease to 7.09 at $8450 \mathrm{~s}$. Thus, VIT5000 was identified as the most effective concentration of the natural surfactant that could provide an environment for obtaining the lowest IFT.

Furthermore, the pictures captured from the crude oil droplets inside distilled water and the prepared surfactant
Fig. 12 Dynamic IFT profiles measured for different crude oil-Vitagnus surfactant solution systems for the period of $150 \mathrm{~min}$

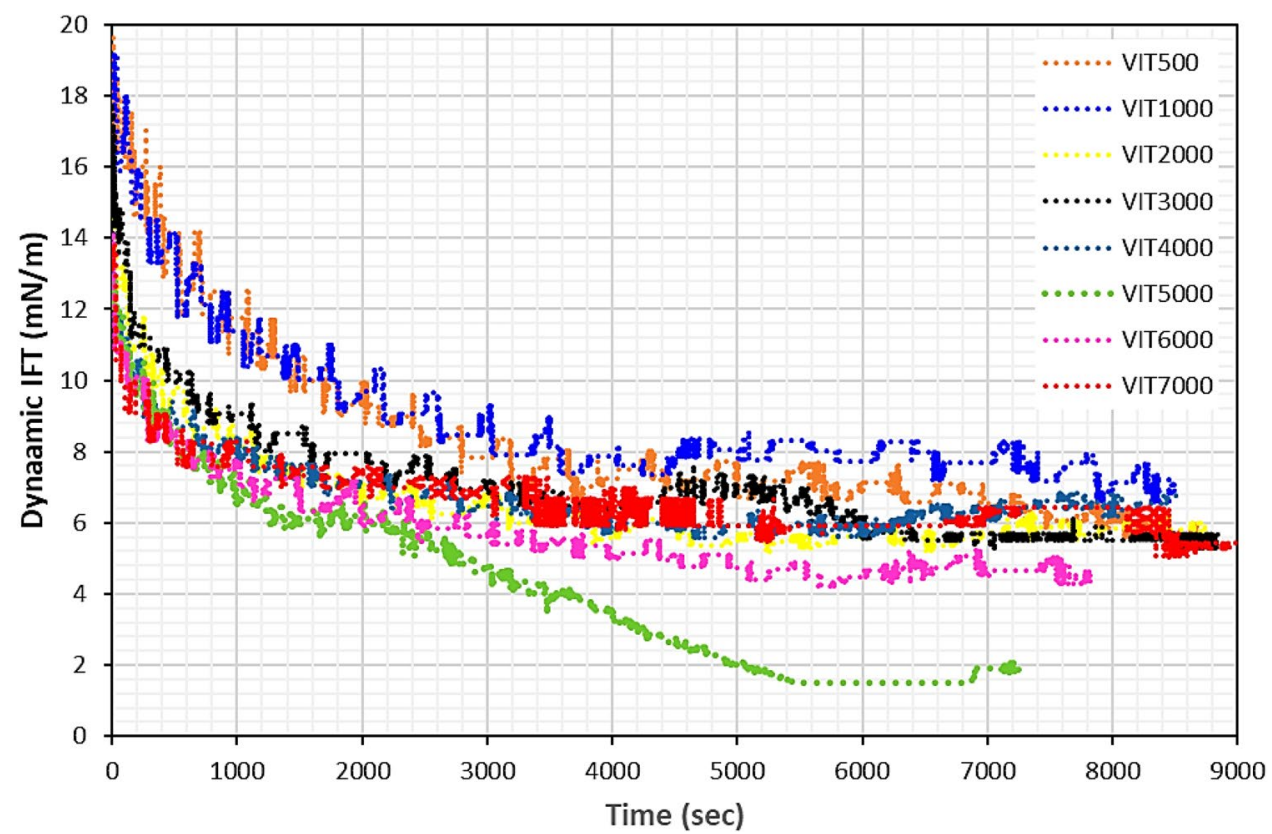




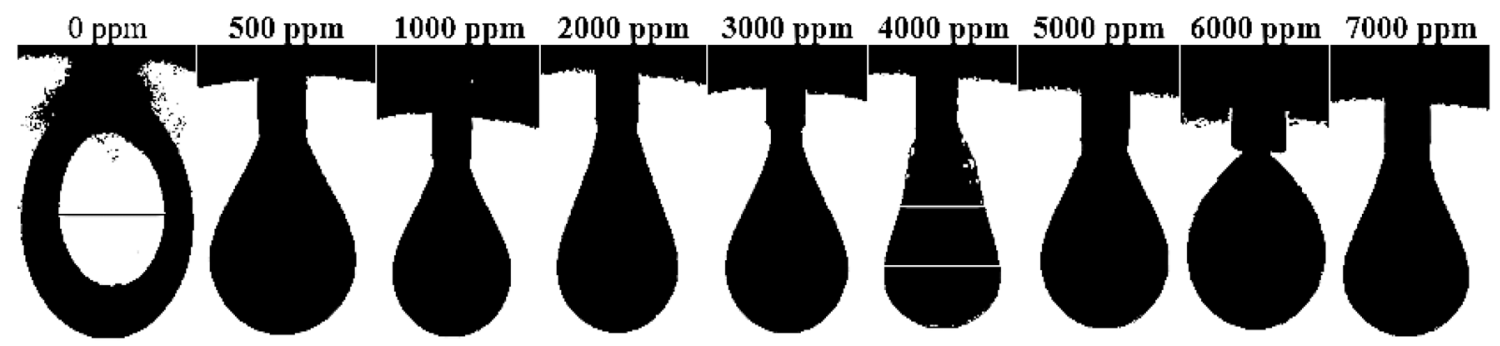

Fig. 13 Shape profiles of crude oil droplets against surfactant solutions

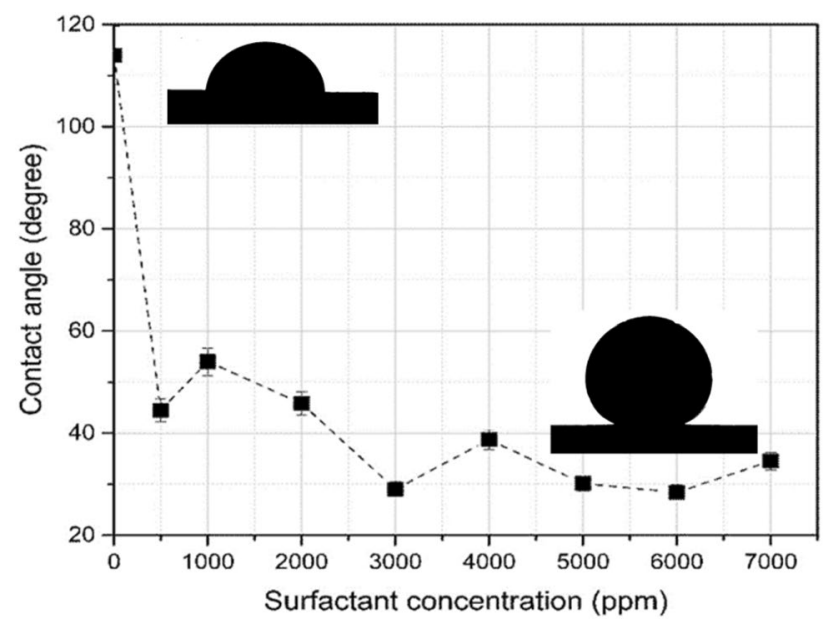

Fig. 14 Contact angle results of crude oil droplets in the presence of the Vitagnus surfactant with concentrations of 500-7000 ppm

solutions are shown in Fig. 13. These droplet shapes represent the minimum static IFT value between the crude oil and the Vitagnus surfactant solution at different concentrations. As are obvious, different shapes of the same crude oil under similar experiment conditions were achieved on the basis of the concentration of the used natural surfactant. This confirms the effect of the surfactant concentration on the crude oil/surfactant interaction.

\section{Contact angle}

Figure 14 presents contact angle values of the oil droplet measured within the prepared surfactant solutions at different concentrations. The maximum contact angle of $114^{\circ}$ was measured for a crude oil droplet when it was immersed in distilled water, which expressed the oil-wet state, according to Fig. 6b (Bagalkot et al. 2018). The wettability state of the carbonate pellets was sharply altered to water-wet by adding $500 \mathrm{ppm}$ of the Vitagnus extract at a $44.5^{\circ}$ contact angle.

The contact angle dropping was continued with an increase in the concentration of the used surfactant. This was very consistent with the descriptions of Teklu et al. (2017) and Kamaei et al. (2019), who used a mixture of the Tween 80 and SDBS solutions to alter the wettability of quartz rocks. The minimum contact angle of $29^{\circ}$ was achieved for both the VIT3000 and the VIT6000 surfactant solutions. Therefore, the surfactant CMC of 3000 ppm could be considered the optimum concentration in the case of the natural surfactant used.

\section{Core-flooding}

The extract of the Vitagnus plant was used as a natural surfactant to prepare different solutions within the distilled water at different concentrations (500-7000 ppm), as mentioned earlier. On the basis of the measured conductivity, $\mathrm{pH}$, and turbidity values, $3000 \mathrm{ppm}$ was identified as the optimal CMC of the used natural surfactant. In addition, the favourable IFT and the minimum contact angle were measured at the same concentration with the VIT3000 surfactant solution. We thus selected the VIT3000 solution for injection into the core plug after the water-flooding (Table 3). By injecting $2 \mathrm{PVs}$ of brine into the core plug, we extracted $44 \%$ OOIP of crude oil from the total pore volume of $9.31 \mathrm{~cm}^{3}$. Thus, the saturation of the oil (Soi) was reduced to $35.3 \%$. Then, to evaluate the performance of the Vitagnus surfactant in terms of the recovery, 2.25 PVs of the VIT3000 surfactant solution were pumped into the core plug displaced by water (see Fig. 15). During the tertiary recovery, an additional $12.8 \%$ OOIP was produced, and the recovery was increased to $56.8 \%$ OOIP. The last oil saturation achieved in the core plug was $27.8 \%$. Although, the value of the IFT is highly reduced to $1.8 \mathrm{mN} / \mathrm{m}$, it can be reported that this considerable improvement in the oil recovery could be attributed by some other mechanisms of EOR including oil/water emulation improvement and the alteration of the wettability.

\section{Conclusions}

The current work focused on the use of the Vitagnus plant extract as a natural surfactant to improve the oil recovery from carbonate oil reservoirs. Thus, several tests were

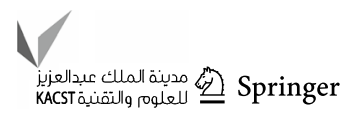




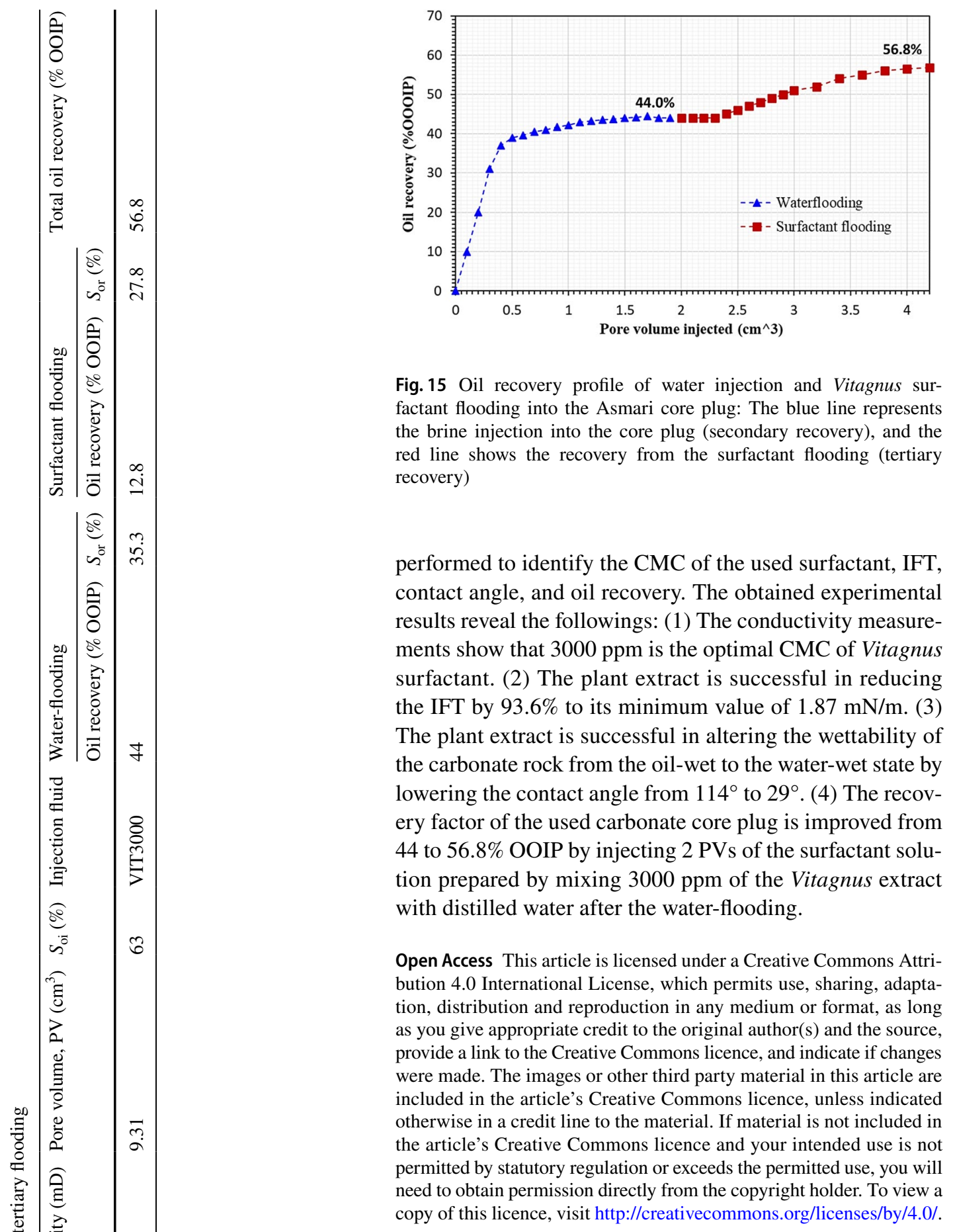

\section{References}

Ahmadi MA, Shadizadeh SR (2013a) Implementation of a high performance surfactant for enhanced oil recovery from carbonate reservoirs. J Petrol Sci Eng 110:66-73. https://doi.org/10.1016/j. petrol.2013a.07.007

Ahmadi MA, Shadizadeh SR (2013b) Induced effect of adding nano silica on adsorption of a natural surfactant onto sandstone rock: 
experimental and theoretical study. J Petrol Sci Eng 112:239-247. https://doi.org/10.1016/j.petrol.2013.11.010

Ahmadi MA, Shadizadeh SR (2018) Spotlight on the new natural surfactant flooding in carbonate rock samples in low salinity condition. Sci Rep 8(1):1-15. https://doi.org/10.1038/s41598-01829321-w

Ahmadi MA, Arabsahebi Y, Shadizadeh SR, Shokrollahzadeh BS (2014) Preliminary evaluation of mulberry leaf-derived surfactant on interfacial tension in an oil-aqueous system: EOR application. Fuel 117:749-755. https://doi.org/10.1016/j.fuel.2013.08.081

Ahmadi MA, Galedarzadeh M, Shadizadeh SR (2015) Wettability alteration in carbonate rocks by implementing new derived natural surfactant: enhanced oil recovery applications. Transp Porous Media 106(3):645-667. https://doi.org/10.1007/s1124 2-014-0418-0

Ali JA, Stephen KD (2018) A semi-analytical method for history matching and improving geological models of layered reservoirs: CGM analytical method. J Chem Petrol Eng 52(1):69-88

Ali JA, Kolo K, Manshad AK, Mohammadi AH (2018) Recent advances in application of nanotechnology in chemical enhanced oil recovery: effects of nanoparticles on wettability alteration, interfacial tension reduction, and flooding. Egypt $\mathrm{J}$ Pet 27(4):1371-1383. https://doi.org/10.1016/j.ejpe.2018.09.006

Ali JA, Kolo K, Manshad AK, Stephen KD, Keshavarz A (2019a) Modification of LoSal water performance in reducing interfacial tension using green $\mathrm{ZnO} / \mathrm{SiO}_{2}$ nanocomposite coated by xanthan. Appl Nanosci 9:397-409. https://doi.org/10.1007/s1320 4-018-0923-5

Ali JA, Kolo K, Manshad AK, Stephen KD (2019b) Low-salinity polymeric nanofluid-enhanced oil recovery using green polymercoated $\mathrm{ZnO} / \mathrm{SiO}_{2}$ nanocomposites in the Upper Qamchuqa formation in Kurdistan Region, Iraq. Energy Fuels 33(2):927-937. https ://doi.org/10.1021/acs.energyfuels.8b03847

Ali JA, Kamal K, Manshad AK, Stephen KD (2019c) Potential application of low-salinity polymeric-nanofluid in carbonate oil reservoirs: IFT reduction, wettability alteration, rheology and emulsification characteristics. J Mol Liq 284:735-747. https://doi. org/10.1016/j.molliq.2019.04.053

Asl HF, Zargar G, Manshad AK, Takassi MA, Ali JA, Keshavarz A (2019) Experimental investigation into 1-Arg and 1-Cys ecofriendly surfactants in enhanced oil recovery by considering IFT reduction and wettability alteration. Petrol Sci 17:105-117. https ://doi.org/10.1007/s12182-019-0354-2

Bagalkot N, Hamouda NN, Isdahl OM (2018) Dynamic interfacial tension measurement method using axisymmetric drop shape analysis. MethodsX 5:676-683

Bera A, Kumar T, Ojha K, Mandal A (2013) Adsorption of surfactants on sand surface in enhanced oil recovery: isotherms, kinetics and thermodynamic studies. Appl Surf Sci 284:87-99. https://doi. org/10.1016/j.apsusc.2013.07.029

Chhetri AB, Watts KC, Rahman MS, Islam MR (2009) Soapnut extract as a natural surfactant for enhanced oil recovery. Energy Sour Part A Recovery Util, Environ Eff 31(20):1893-1903. https://doi. org/10.1080/15567030802462622

Daghlian JS, Sharifi SM, Sarapardeh AH (2016) Toward mechanistic understanding of natural surfactant flooding in enhanced oil recovery processes: the role of salinity, surfactant concentration and rock type. J Mol Liq 222:632-639. https://doi.org/10.1016/j. molliq.2016.07.086

Deymeh H, Shadizadeh S, Motafakkerfard R (2012) Experimental investigation of Seidlitzia rosmarinus effect on oil-water interfacial tension: usable for chemical enhanced oil recovery. Scientia Iranica 19(6):1661-1664. https://doi.org/10.1016/j.scien t.2012.04.020

Hanamertani AS, Pilus RM, Idris AK, Irawan S, Tan IM (2017) Ionic liquids as a potential additive for reducing surfactant adsorption onto crushed Berea sandstone. J Petrol Sci Eng 162:480-490. https://doi.org/10.1016/j.petrol.2017.09.077

Howe AM, Clarke A, Mitchell J, Staniland J, Hawkes L, Whalan C (2015) Visualising surfactant enhanced oil recovery. Colloids Surf A 480:449-461. https://doi.org/10.1016/j.colsurfa.2014.08.032

Kamaei E, Manshad AK, Shadizadeh SR, Ali JA, Keshavarz A (2019) Effect of the wettability alteration on the cementation factor of carbonate rocks using Henna extract. Materialia 8:100440. https ://doi.org/10.1016/j.mtla.2019.100440

Kamal MS, Sultan AS, Hussein IA (2015) Screening of amphoteric and anionic surfactants for cEOR applications using a novel approach. Colloids Surf A 476:17-23. https://doi.org/10.1016/j. colsurfa.2015.03.023

Kumar S, Mandal A (2016) Studies on interfacial behavior and wettability change phenomena by ionic and nonionic surfactants in presence of alkalis and salt for enhanced oil recovery. Appl Surf Sci 372:42-51. https://doi.org/10.1016/j.apsusc.2016.03.024

Manshad AK, Rezaei M, Moradi S, Nowrouzi I, Mohammadi AH (2017) Wettability alteration and interfacial tension (IFT) reduction in enhanced oil recovery (EOR) process by ionic liquid flooding. J Mol Liq 248:153-162. https://doi.org/10.1016/j.molli q.2017.10.009

Mari A, Montoro P, Pizza C, Piacente S (2012) Liquid chromatography tandem mass spectrometry determination of chemical markers and principal component analysis of Vitex agnus-castus L. fruits (Verbenaceae) and derived food supplements. J Pharm Biomed Anal 70:224-230. https://doi.org/10.1016/j.jpba.2012.07.001

Najimi S, Nowrouzi I, Manshad AK, Farsangi MH, Hezave AZ, Ali JA, Keshavarz A, Mohammadi AH (2019) Investigating the effect of $[\mathrm{C} 8 \mathrm{Py}][\mathrm{Cl}]$ and $[\mathrm{C} 18 \mathrm{Py}][\mathrm{Cl}]$ ionic liquids on the water/ oil interfacial tension by considering Taguchi method. J Petrol Explor Prod Technol 9:2933-2941. https://doi.org/10.1007/s1320 2-019-0688-8

Olayiwola SO, Dejam M (2019) A comprehensive review on interaction of nanoparticles with low salinity water and surfactant for enhanced oil recovery in sandstone and carbonate reservoirs. Fuel 241:1045-1057. https://doi.org/10.1016/j.fuel.2018.12.122

Pal N, Saxena N, Laxmi KVD, Mandal A (2018) Interfacial behaviour, wettability alteration and emulsification characteristics of a novel surfactant: implications for enhanced oil recovery. Chem Eng Sci 187:200-212. https://doi.org/10.1016/j.ces.2018.04.062

Pawar S, Kamble V (2017) Phytochemical screening, elemental and functional group analysis of vitex negundo 1 . Leaves Int $\mathrm{J}$ Pharm Pharm Sci 9(6):226. https://doi.org/10.22159/ijpps.2017v 9i6.18093

Saha R, Uppaluri RV, Tiwari P (2018) Effects of interfacial tension, oil layer break time, emulsification and wettability alteration on oil recovery for carbonate reservoirs. Colloids Surf A 559:92-103. https://doi.org/10.1016/j.colsurfa.2018.09.045

Teklu TW, Alameri W, Kazemi H, Graves RM, AlSumaiti AM (2017) Low salinity water-Surfactant-CO2 EOR. Petroleum 3(3):309-320

Wang Y, Zhao F, Bai B (2010) Optimized surfactant IFT and polymer viscosity for surfactant-polymer flooding in heterogeneous formations. In: SPE improved oil recovery symposium, SPE 127391MS, April 24-28, 2010, Tulsa, OK, USA. Society of Petroleum Engineers. https://doi.org/10.2118/127391-ms

Wuttke W, Jarry H, Christoffel V, Spengler B, Seidlová-Wuttke D (2003) Chaste tree (Vitex agnus-castus) - pharmacology and clinical indications. Phytomedicine 10(4):348-357

Publisher's Note Springer Nature remains neutral with regard to jurisdictional claims in published maps and institutional affiliations. 